\title{
Safety and Efficacy of Ambrisentan-Phosphodiesterase Type 5 (PDE5) Inhibitor Combination Therapy for Japanese Pulmonary Arterial Hypertension Patients in Real-World Clinical Practice
}

\author{
Masaharu Kataoka, MD, PhD; Toru Satoh, MD, PhD; Hiromi Matsubara, MD, PhD; \\ Koji Yamamoto, MD, PhD; Tsukasa Inada, MD, PhD; Kazunari Umezawa; \\ Tomohiko Takahashi; Atsushi Nakano, MD, PhD; Keiichi Fukuda, MD, PhD
}

\begin{abstract}
Background: This retrospective study was conducted to evaluate the safety and efficacy of ambrisentan combination therapy with phosphodiesterase type 5 (PDE5) inhibitors in Japanese patients with pulmonary arterial hypertension (PAH).

Methods and Results: PAH patients who received ambrisentan for the first time in combination with a PDE5 inhibitor between January 2013 and the end of August 2015 were included in this study. Adverse drug reaction (ADR) safety analysis, as well as the efficacy analysis focusing on changes in clinical parameters, were investigated for overall cases and cases stratified by patient background. Forty-eight consecutive patients ( $n=21,43.8 \%$ with idiopathic $\mathrm{PAH}$; male/female, 18/30; average age, $43.3 \pm 17.4$ years; World Health Organization functional class III/IV, $\mathrm{n}=22,45.8 \%$ ) who were treated with ambrisentan and a PDE5 inhibitor in Japan underwent the safety analysis. A total of 14 ADR occurred in 10 patients (20.8\%). ADR included headache (8.3\%), face edema $(4.2 \%)$, angina pectoris $(2.1 \%)$, hyperemia (2.1\%), dyspnea (2.1\%), pulmonary hypertension (i.e., worsening of PAH, $2.1 \%)$, nausea $(2.1 \%)$, hepatic function abnormal $(2.1 \%)$, edema $(2.1 \%)$, and sudden death $(2.1 \%)$. On analysis of hemodynamics parameters, there was a significant improvement in the mean pulmonary arterial pressure $(-13.5 \mathrm{mmHg}, \mathrm{P}=0.0001)$ and pulmonary vascular resistance $\left(-563.53 \mathrm{dyn} \cdot \mathrm{s} \cdot \mathrm{cm}^{-5}, \mathrm{P}=0.0033\right)$.
\end{abstract}

Conclusions: Ambrisentan combination therapy is safe and effective in hemodynamics improvement.

Key Words: Ambrisentan; Combination therapy; Hemodynamics; Phosphodiesterase type 5 inhibitor; Pulmonary arterial hypertension

$\mathbf{P}$ ulmonary arterial hypertension (PAH) is a progressive and multifactorial disorder that leads to right ventricular overload associated with right-sided heart failure. PAH is associated with significant morbidity and mortality, with a 5-year survival rate of $34 \%$ in untreated patients, according to a historic national registry in the USA. ${ }^{1}$ Meanwhile, the 5-year survival rate in idiopathic/heritable PAH patients was $96 \%$ according to the latest report in a Japanese PAH expert center. ${ }^{2}$ This remarkable improvement was brought about by aggressive use of PAH-targeted drugs including combination therapy with i.v. epoprostenol. ${ }^{3}$ Due to the progressive nature and severity of the disease, the trend in the treatment strategy for PAH has evolved from monotherapy to combination therapy to improve prognosis. The usefulness of combination therapy has been corroborated by multiple randomized controlled trials (RCT) as well as by a meta-analysis showing that combination therapy was associated with a significant $38 \%$ reduction of risk of combined clinical worsening events (15 RCT: $n=3,906$; risk ratio [RR], 0.62 ; $95 \% \mathrm{CI}$ : $0.50-0.77) \cdot{ }^{4-7}$ Combination therapy was also associated with improvement in 6-min walking distance (10 RCT: $n=1,553$; weighted mean difference [WMD], $+23.0 \mathrm{~m}$; 95\% CI: $15.9-$ 30.1 ), improved functional class (9 RCT: $n=1,737$; RR, 1.26; 95\% CI: 1.05-1.51), and beneficial effects on pulmonary hemodynamics such as cardiac index (WMD, $+0.35 \mathrm{~L} / \mathrm{min} / \mathrm{m}$; 95\% CI: $0.14-0.56){ }^{7}$

Initial combination therapy with ambrisentan (an

Received April 3, 2019; revised manuscript received April 23, 2019; accepted April 25, 2019; J-STAGE Advance Publication released online May 29, 2019 Time for primary review: 1 day

Department of Cardiology, Keio University School of Medicine, Tokyo (M.K., K.F.); Department of Cardiology, Kyorin University School of Medicine, Tokyo (T.S.); Department of Cardiology, National Hospital Organization Okayama Medical Center, Okayama (H.M.); Department of Cardio-Renal Medicine and Hypertension, Nagoya City University Graduate School of Medical Sciences, Aichi (K.Y.); Department of Cardiology, Cardiovascular Center, Osaka Red Cross Hospital, Osaka (T.I.); and Medical Affairs, GlaxoSmithKline K.K., Tokyo (K.U., T.T., A.N.), Japan

Mailing address: Keiichi Fukuda, MD, PhD, Department of Cardiology, Keio University School of Medicine, 35 Shinanomachi, Shinjuku-ku, Tokyo 160-8582, Japan. E-mail: kfukuda@a2.keio.jp

ISSN-2434-0790 All rights are reserved to the Japanese Circulation Society. For permissions, please e-mail: cr@j-circ.or.jp 


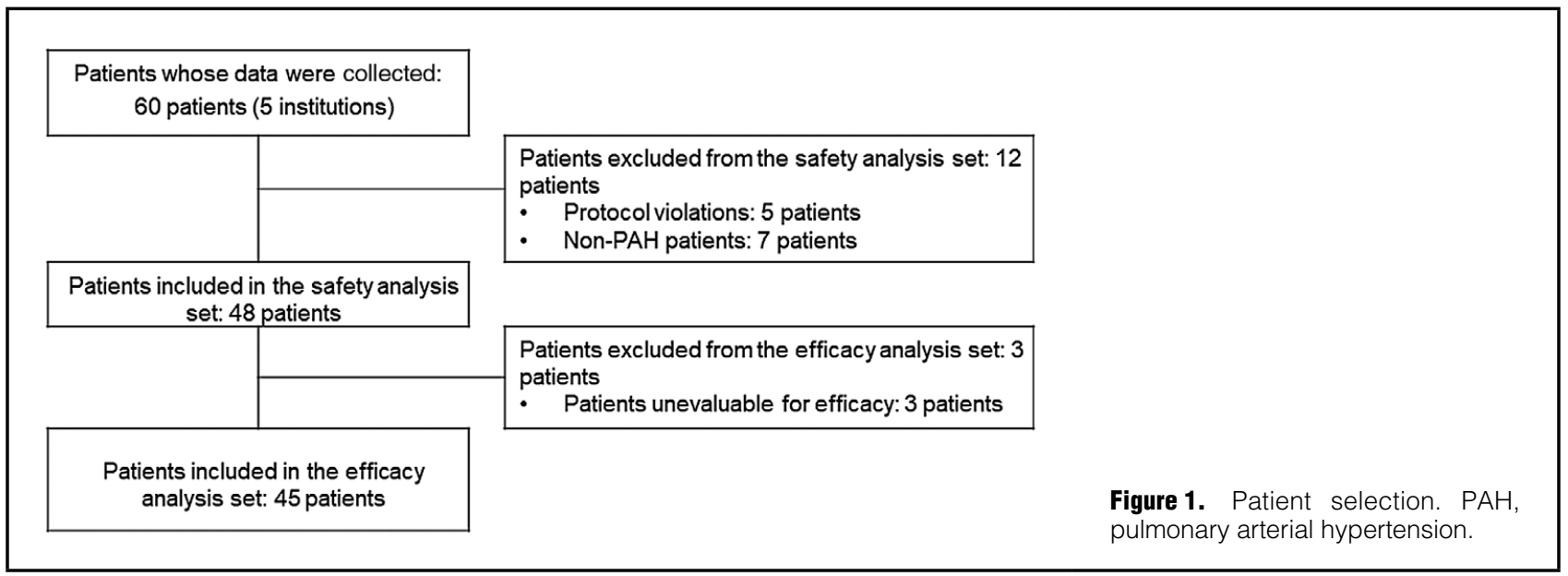

endothelin receptor antagonist [ERA]) and tadalafil (a phosphodiesterase type 5 [PDE5] inhibitor) resulted in a significantly lower risk of clinical failure events than that for ambrisentan or tadalafil monotherapy in the large event-driven AMBITION study. ${ }^{4}$ The latest European Society of Cardiology (ESC) and European Respiratory Society (ERS) guidelines recommend that the concurrent use of 2 drugs beginning in the initial stage in naïve and adult patients with PAH should be considered. ${ }^{8}$

Information on the safety and effectiveness of these combination therapies in Japanese patients, however, is limited. Therefore, we conducted a retrospective survey in Japanese patients to gather information on the safety and efficacy of ambrisentan combination therapy with PDE5 inhibitor (i.e., tadalafil and sildenafil).

\section{Methods}

This investigation was initiated to assess the long-term safety and efficacy and clinical course in patients using ambrisentan and a PDE5 inhibitor in real-world clinical practice as a special drug use investigation. This investigation was conducted in accordance with the Japanese Good Post-Marketing Study Practice (GPSP; Ordinance of Ministry of Health, Labour and Welfare No. 171 of December 20, 2004), and the study protocol was reviewed and approved by each site's institutional review board before the study began. Informed consent was not required from the individual participants included in this survey according to the GPSP. A written contract was concluded with the institution before the initiation of the survey and an agreement for the publication of this survey was obtained from all participating institutions. The subjects of this survey were PAH patients who received ambrisentan for the first time in combination with PDE5 inhibitors as an initial combination therapy or sequential combination therapy between January 2013 and the end of August 2015. Initial combination therapy was defined as treatment with ambrisentan and approved PDE5 inhibitors (tadalafil or sildenafil) concomitantly, or treatment with ambrisentan $\leq 30$ days after PDE5 inhibitors, and sequential combination therapy was defined as addition of ambrisentan after suboptimal response to background PDE5 inhibitors. This survey was conducted using the continuous survey system to consecutively select patients from the participating institutions so that no bias occurred during the patient selection process. The clinical classification of PAH was carried out with an old version used in a Japanese phase 3 clinical trial. ${ }^{9}$ The rules of personal data confidentiality were fully respected.

\section{Subjects}

In this survey, data on PAH patients aged $\geq 15$ years who were treated with ambrisentan and a PDE5 inhibitor at 5 institutions specializing in the treatment of $\mathrm{PAH}$ where both drugs are adopted and to which they are supplied, were collected. The institutions were Keio University Hospital, Kyorin University Hospital, Okayama Medical Center, Nagoya City University Hospital, or Japanese Red Cross Osaka Hospital in Japan. In Japan, pediatric use is generally defined as use in patients aged $<15$ years old.

\section{Observation Period}

The patients were observed for $\geq 1$ year and this was extended up to 3 years, with patient cooperation.

\section{Collected Information}

Items of investigation included patient characteristics, patient data before and during combination treatment (laboratory test data, patient status, cardiopulmonary hemodynamics), and PAH treatment history before and during the combination treatment. For safety and efficacy analysis, the following data were obtained at baseline; 1 month after the initiation of combination therapy; and every 3 months in the follow-up period: incidence of adverse events (AE), type of AE, occurrence date, outcomes, severity, causal relationship with ambrisentan, cause of the AE, World Health Organization (WHO) pulmonary hypertension functional class (WHO-FC), 6-min walk distance (6MWD), B-type natriuretic peptide (BNP), N-terminal prohormone BNP (NT-proBNP), tricuspid regurgitant pressure gradient (TRPG), and diameters of the inferior vena cava on echocardiography. Cardiopulmonary hemodynamics parameters determined on right heart catheterization included mean right atrial pressure (RAP), mean pulmonary artery pressure (mPAP), mean pulmonary artery wedge pressure (PAWP), cardiac output $(\mathrm{CO})$, pulmonary vascular resistance (PVR), and oxygen saturation $\left(\mathrm{SaO}_{2}\right)$. The clinical parameters, especially hemodynamics, were measured at the investigator's discretion depending on 
Table 1. Safety Analysis: Patient Characteristics $(n=48)$

\begin{tabular}{|c|c|c|c|}
\hline & All patients & $\begin{array}{l}\text { Initial combination } \\
\text { treatment }\end{array}$ & $\begin{array}{c}\text { Sequential combination } \\
\text { treatment }\end{array}$ \\
\hline No. patients & $48(100)$ & $20(41.7)$ & $28(58.3)$ \\
\hline Follow-up period (days) & $335.9 \pm 215.1$ & $319.9 \pm 246.5$ & $347.3 \pm 193.6$ \\
\hline Female & $30(62.5)$ & $13(65.0)$ & $17(60.7)$ \\
\hline Age (years) & $43.3 \pm 17.4$ & $41.5 \pm 11.8$ & $44.5 \pm 20.6$ \\
\hline \multicolumn{4}{|l|}{ PAH classification } \\
\hline Primary & $25(52.1)$ & $11(55.0)$ & $14(50.0)$ \\
\hline IPAH & $21(43.8)$ & $8(40.0)$ & $13(46.4)$ \\
\hline FPAH & $4(8.3)$ & $3(15.0)$ & $1(3.6)$ \\
\hline Secondary & $23(47.9)$ & $9(45.0)$ & $14(50.0)$ \\
\hline $\mathrm{CHD}$ with a shunt & $7(14.6)$ & 0 & $7(25.0)$ \\
\hline CTD & $8(16.7)$ & $3(15.0)$ & $5(17.9)$ \\
\hline Portal hypertension & $7(14.6)$ & $5(25.0)$ & $2(7.1)$ \\
\hline Others & $6(12.5)$ & $1(5.0)$ & $5(17.9)$ \\
\hline 6MWD (m) & $300.7 \pm 185.9(n=11)$ & $271.2 \pm 184.7(n=9)$ & $433.5 \pm 171.8(n=2)$ \\
\hline \multicolumn{4}{|l|}{ WHO-FC } \\
\hline 1 & $2(4.2)$ & $2(10.0)$ & 0 \\
\hline II & $22(45.8)$ & $7(35.0)$ & $15(53.6)$ \\
\hline III & $19(39.6)$ & $9(45.0)$ & $10(35.7)$ \\
\hline IV & $3(6.3)$ & $1(5.0)$ & $2(7.1)$ \\
\hline Unknown or unlisted & $2(4.2)$ & $1(5.0)$ & $1(3.6)$ \\
\hline PAWP (mmHg) & $8.9 \pm 3.6(n=33)$ & $8.1 \pm 3.3(n=18)$ & $9.8 \pm 3.8(n=15)$ \\
\hline mPAP $(\mathrm{mmHg})$ & $42.5 \pm 18.0(n=35)$ & $50.2 \pm 19.3(n=19)$ & $33.3 \pm 10.9(n=16)$ \\
\hline $\mathrm{CO}(\mathrm{L} / \mathrm{min})$ & $4.5 \pm 2.1(n=32)$ & $4.0 \pm 2.1(n=18)$ & $5.2 \pm 1.8(n=14)$ \\
\hline PVR (dyn $\cdot s \cdot \mathrm{cm}^{-5}$ ) & $809.6 \pm 630.9(n=32)$ & $1,054.3 \pm 665.4(n=19)$ & $452.0 \pm 361.8(n=13)$ \\
\hline TRPG $(\mathrm{mmHg})$ & $63.0 \pm 22.7(n=32)$ & $73.5 \pm 25.5(n=16)$ & $52.4 \pm 13.4(n=16)$ \\
\hline
\end{tabular}

Data given as mean \pm SD or $\mathrm{n}(\%)$. 6MWD, 6-min walk distance; $\mathrm{CHD}$, congenital heart disease; CO, cardiac output; CTD, connective tissue disease; FC, function class; FPAH, familial pulmonary arterial hypertension; IPAH, idiopathic pulmonary arterial hypertension; mPAP, mean pulmonary arterial pressure; PAH, pulmonary arterial hypertension; PAWP, mean pulmonary arterial wedge pressure; PVR, pulmonary vascular resistance; TRPG, tricuspid regurgitant pressure gradient; WHO, World Health Organization.

\begin{tabular}{|lc|}
\hline \multicolumn{2}{|l|}{ Table 2. Concomitant Medication } \\
PDE5i ${ }^{\dagger}$ \\
Tadalafil \\
Sildenafil \\
PGI2 & $34(70.8)$ \\
Beraprost & $21(43.8)$ \\
Epoprostenol & \\
Anticoagulants & $17(35.4)$ \\
Warfarin & $12(25.0)$ \\
Diuretics & \\
Furosemide & $5(10.4)$ \\
Spironolactone & \\
Torasemide & $27(56.3)$ \\
Tolvaptan & $12(25.0)$ \\
Azosemide & $6(12.5)$ \\
Trichlormethiazide & $3(6.3)$ \\
\hline
\end{tabular}

Data given as $\mathrm{n}(\%)$ including overlapping. +Some patients switched to another PDE5i. PDE5i, phosphodiesterase type 5 inhibitor; PGI2, prostaglandin 12.

local clinical settings.

\section{Data Analysis}

For safety analysis, data from all AE that occurred after the beginning of treatment with ambrisentan were collected, regardless of whether they were considered related to ambrisentan. When a relationship with ambrisentan was judged by the physician to be present based on clinical evaluation and according to the reference safety information, the $\mathrm{AE}$ was treated as an adverse drug reaction (ADR) during the acquisition of safety information. In the safety analysis, the incidence rate for AE and ADR was calculated by dividing the number of patients with an AE or ADR by the total number of patients included in the safety analysis. MedDRA version 20.1 was used for the coding of ADR, and the ADR were reported to the regulatory authority. The efficacy analysis included patients in whom each parameter was examined at least once before and after ambrisentan treatment. Variations in parameters before and after treatment with ambrisentan were analyzed in all evaluable patients by comparing the baseline values (values obtained before treatment) and post-treatment test values (values obtained in the final test conducted during the observation period). Differences between baseline and posttreatment parameters were tested for statistical significance using the paired Wilcoxon test.

\section{Results}

\section{Patient Selection}

Patient selection is shown in Figure 1. Of 60 patients assessed in this study, 48 patients, excluding those who violated the 
Table 3. Safety Analysis Set: ADR

\begin{tabular}{lccc} 
All patients & $\begin{array}{c}\text { Initial combination } \\
\text { treatment }\end{array}$ & $\begin{array}{c}\text { Sequential combination } \\
\text { treatment }\end{array}$ \\
$\begin{array}{l}\text { No. patients } \\
\text { No. patients with onset of ADR }\end{array}$ & 48 & 20 & 28 \\
No. ADR & $10(20.8)$ & $5(25.0)$ & $5(17.9)$ \\
No. events by type of ADR & 14 & 6 & 8 \\
Headache & & & $2(7.1)$ \\
Face edema & $4(8.3)$ & $2(10.0)$ & $1(3.6)$ \\
Angina pectoris & $2(4.2)$ & $1(5.0)$ & 0 \\
Hyperemia & $1(2.1)$ & $1(5.0)$ & $1(3.6)$ \\
Dyspnea & $1(2.1)$ & 0 & 0 \\
Pulmonary hypertension & $1(2.1)$ & $1(5.0)$ & $1(3.6)$ \\
Nausea & $1(2.1)$ & 0 & $1(3.6)$ \\
Hepatic function abnormal & $1(2.1)$ & 0 & 0 \\
Edema & $1(2.1)$ & $1(5.0)$ & $1(3.6)$ \\
Sudden death & $1(2.1)$ & 0 & $1(3.6)$ \\
\hline
\end{tabular}

Data given as $n$ (\%). MedDRA version 20.1 was used for the coding of ADR, and the ADR were reported to the regulatory authority and used for the present analysis. ADR, adverse drug reaction.

study protocol (e.g., patients who have already been treated with ambrisentan at other institutions) and those who were recognized as having non-PAH from comorbidity information, underwent safety analysis. Of the subjects included in the safety analysis, 3 were excluded from the efficacy analysis because of unavailable results. Thus, 45 patients were included in the efficacy analysis.

The diagnoses in the non-PAH patients were: pulmonary hypertension associated with pulmonary venous obstruction in 3 patients, pulmonary hypertension associated with chronic obstructive pulmonary disease in 1 patient, pulmonary hypertension associated with hypoxemia in 1 patient, pulmonary hypertension associated with chronic pulmonary thromboembolism in 1 patient, and pulmonary hypertension associated with idiopathic pulmonary fibrosis in 1 patient.

\section{Patient Characteristics}

The characteristics of the 48 patients in the safety analysis are listed in Table 1. There were 30 female patients $(62.5 \%)$, and the overall mean patient age was $43.3 \pm 17.4$ years old. Of those with primary PAH, idiopathic PAH was found in 21 patients $(43.8 \%)$. Mean baseline 6MWD was $300.7 \pm 185.9 \mathrm{~m}$. In total, $85.4 \%$ of the patients were categorized in WHO-FC II-III. Concomitant medications are listed in Table 2. The background of patients who underwent the initial combination therapy was more severe than that of those who underwent sequential combination therapy in mPAP, PVR, 6MWD, and TRPG (e.g., baseline mPAP: $50.2 \pm 19.3 \mathrm{mmHg}$ for initial combination therapy vs. $33.3 \pm 10.9 \mathrm{mmHg}$ for sequential combination therapy). As noted, the clinical classification of PAH in this survey was carried out according to that used in a Japanese phase 3 clinical trial. ${ }^{9}$

\section{Safety}

A total of 14 ADR occurred in 10 patients $(20.8 \%)$. Common ADR included headache $(8.3 \%)$, face edema (4.2\%), angina pectoris $(2.1 \%)$, hyperemia $(2.1 \%)$, dyspnea $(2.1 \%)$, pulmonary hypertension $(2.1 \%)$, nausea $(2.1 \%)$, hepatic function abnormal $(2.1 \%)$, edema $(2.1 \%)$, and sudden death $(2.1 \%)$.

\begin{tabular}{|lcc|}
\hline \multicolumn{2}{|c|}{ Table 4. Outcomes of Serious ADR } & \\
Serious ADR & $\mathbf{n}(\%)$ & Outcome \\
Angina pectoris & $1(2.1)$ & Remission \\
Hepatic function abnormal & $1(2.1)$ & Recovery \\
Pulmonary hypertension & $1(2.1)$ & Death \\
Sudden death & $1(2.1)$ & Death \\
\hline
\end{tabular}

ADR, adverse drug reaction.

There were no differences in the incidence and types of ADR in relation to the initial or sequential combination treatments (Table 3). A safety analysis by presence/absence of connective tissue disease associated with PAH (CTD$\mathrm{PAH}$ ) is given in Supplementary Table 1. A higher incidence rate of headache $(10.0 \%)$ and face edema $(5.0 \%)$ was observed in non-CTD-PAH patients, but the reason for this could not be identified because of the small sample size of non-CTD-PAH patients. Serious ADR were found in 4 patients $(8.3 \%)$ : 1 each with angina pectoris $(2.1 \%)$, hepatic function abnormal $(2.1 \%)$, pulmonary hypertension $(2.1 \%)$, and sudden death (2.1\%; Table 4). Of the 4 patients who had serious ADR, the 2 who died (i.e., the pulmonary hypertension patient and the patient who had sudden death) had both received the sequential combination therapy. In the patient who had pulmonary hypertension (male, 18 years old), this was regarded as worsening of PAH. In the case of the sudden death, this occurred at 469 days after ambrisentan treatment, and that patient (male, 73 years old) had complications of epilepsy, primary biliary cirrhosis, chronic kidney disease, mixed CTD, constipation, anemia, and heart failure. The angina pectoris occurred at 20 days after ambrisentan treatment and that patient (female, 34 years old) had known angina pectoris. And the hepatic function abnormal occurred at 44 days after ambrisentan treatment in a female patient (44 years old) with the complications of heart failure, heart aneurysm and stomach polyps. Of the 6 patients with non-serious ADR, in 4 patients the ADR completely resolved, and in 2 patients the ADR were lessened in severity. 


\begin{tabular}{|c|c|c|c|c|c|c|c|c|c|c|}
\hline Type of ADR & $\leq 1 \mathrm{M}$ & 1-3 M & $3-6 M$ & $6-9 M$ & 9-12 M & $12-24 M$ & 24-36 M & $>36 \mathrm{M}$ & Unknown & No. ADR \\
\hline Headache & 1 & 0 & 1 & 0 & 0 & 0 & 0 & 0 & 2 & $4(8.3)$ \\
\hline Angina pectoris & 1 & 0 & 0 & 0 & 0 & 0 & 0 & 0 & 0 & $1(2.1)$ \\
\hline Hyperemia & 0 & 0 & 0 & 0 & 0 & 0 & 0 & 0 & 1 & $1(2.1)$ \\
\hline Dyspnea & 1 & 0 & 0 & 0 & 0 & 0 & 0 & 0 & 0 & $1(2.1)$ \\
\hline Pulmonary hypertension & 0 & 0 & 0 & 0 & 0 & 0 & 0 & 0 & 1 & $1(2.1)$ \\
\hline Nausea & 0 & 0 & 0 & 0 & 0 & 0 & 0 & 0 & 1 & $1(2.1)$ \\
\hline Hepatic function abnormal & 0 & 1 & 0 & 0 & 0 & 0 & 0 & 0 & 0 & $1(2.1)$ \\
\hline Face edema & 1 & 0 & 0 & 0 & 0 & 0 & 0 & 0 & 1 & $2(4.2)$ \\
\hline Edema & 0 & 0 & 0 & 0 & 0 & 0 & 0 & 0 & 1 & $1(2.1)$ \\
\hline Sudden death & 0 & 0 & 0 & 0 & 0 & 1 & 0 & 0 & 0 & $1(2.1)$ \\
\hline
\end{tabular}

Data given as $\mathrm{n}(\%)$. ADR, adverse drug reaction; $\mathrm{M}$, month(s).

Of 7 ADR for which the incidence time could be confirmed, 4 ADR occurred $\leq 1$ month after the initiation of combination therapy, although the date of occurrence was not identified for another 7 ADR (Table 5). Therefore, careful observation in the early treatment period is required to detect ADR as early as possible. Headache and edema are the major ADR of drugs such as ambrisentan with vasodilating effects. In this study, headache (4 events), edema ( 1 event), and face edema ( 2 events) either resolved or lessened in severity after discontinuation of the ambrisentan. The estimated 1-year survival rate from initiation of ambrisentan was $97.4 \%$.

\section{Efficacy}

Change in PAH-Related Parameters Change in PAHrelated parameters after combination treatment is given in Table 6. In this study, the final hemodynamic test was performed at a mean of $220.4 \pm 123.2$ days (median, 255 days) after the initiation of combination therapy. A significant improvement in mPAP $(-13.5 \mathrm{mmHg}$, decreased by $26 \%, \mathrm{P}=0.0001)$ and in $\mathrm{PVR}\left(-563.5 \mathrm{dyn} \cdot \mathrm{s} \cdot \mathrm{cm}^{-5}\right.$, decreased by $23.8 \%, \mathrm{P}=0.0033$ ) was seen after treatment with ambrisentan. The change in parameters in patients receiving i.v. epoprostenol combination therapy, and according to CTD-PAH status, and according to type of combination therapy, is given in Supplementary Table 2. Similar reductions in hemodynamics were observed with concomitant use of epoprostenol.

Change in WHO-FC After Combination Therapy The changes in WHO-FC from baseline to 12 months after treatment are shown in Figure 2. The proportion of patients classified as WHO-FC III decreased. Patients classified as WHO-FC II accounted for $42.1 \%$ at baseline, whereas the corresponding rates were $63.6 \%$ and $66.7 \%$ at 6 and 12 months, respectively. The rate of improvement of WHOFC by at least 1 grade was $36.4 \%$ and $33.3 \%$ at 6 and 12 months, respectively.

\section{Discussion}

In the present study, significant improvement was seen in $\operatorname{mPAP}(-13.5 \mathrm{mmHg}$, decreased by $26 \%, \mathrm{P}=0.0001)$ and in PVR $\left(-563.5 \mathrm{dyn} \cdot \mathrm{s} \cdot \mathrm{cm}^{-5}\right.$, decreased by $\left.23.8 \%, \mathrm{P}=0.0033\right)$, and the safety profile was consistent with previous clinical trials in Japan, and globally in Japanese PAH patients treated with ambrisentan and a PDE5 inhibitor. The benefit of combination therapy with ambrisentan and a PDE5 inhibitor was corroborated in Japanese PAH patients in a real-world clinical practice setting.

This study was conducted as post-marketing surveillance (PMS) to evaluate the safety and efficacy of ambrisentan and a PDE5 inhibitor, focusing on ERA and PDE5 inhibitor combination therapy, which is frequently used in real-world clinical practice. An interim PMS analysis of the safety and efficacy of ambrisentan in 702 patients with PAH noted an ADR rate of 29.1\% (204 patients, 324 events). ${ }^{10}$ Common ADR $(\geq 2 \%)$ included anemia (4.6\%), peripheral edema $(4.1 \%)$, headache $(3.6 \%)$, edema and face edema (2.6\% each), abnormal hepatic function $(2.3 \%)$, and epistaxis $(2.1 \%)$. A total of 82 serious ADR occurred in 44 patients $(6.3 \%, 44 / 702)$, although these interim PMS data included patients who underwent only ambrisentan monotherapy. ${ }^{10}$ There was no difference in safety with regard to the presence/absence of CTD-PAH. ${ }^{10}$ Furthermore, in the interim PMS analysis, the incidence of ADR for the ambrisentan combination with tadalafil and sildenafil was consistent with that for all patients as a whole. ${ }^{10}$ The safety evaluations for the initial combination or sequential combination with PDE5 inhibitors in the PMS interim analysis were difficult because the detailed treatment period of the concomitant drugs specific to $\mathrm{PAH}$, including PDE5 inhibitors, was not obtained in the case report form. ${ }^{10}$ The present study is the first in which the treatment period of the combination therapy with PDE5 inhibitors was closely investigated, and the subjects were limited to Japanese patients receiving initial or sequential combination therapy at expert centers where PAH specialists were available. The present results are consistent with the AMBITION study, which investigated the efficacy and safety of initial combination therapy, ${ }^{4}$ although we need to keep in mind that the AMBITION study evaluated the combination of ambrisentan with tadalafil as a PDE5 inhibitor. Based on the AMBITION results, along with some other smaller mostly uncontrolled studies, the ESC/ERS guidelines and Japanese guidelines for the diagnosis and treatment of pulmonary hypertension (revised 2017 edition) were specified, and for the first time, the concurrent use of PAH drugs in the initial stage should be considered for treatment-naïve $\mathrm{PAH}$ patients. ${ }^{\mathbf{8}, 11}$ Currently, combination therapy is considered to be a core treatment strategy for $\mathrm{PAH}$, aimed at further improvement of treatment. Regarding safety, in the AMBITION study, peripheral edema $(45 \%)$ and headache $(42 \%)$ were more common AE in the combination therapy group than in the monotherapy group. ${ }^{4}$ Frequent ADR in 


\begin{tabular}{|c|c|c|c|c|}
\hline & & $\mathbf{n}$ & Mean \pm SD & $\begin{array}{l}\text { Mean of variation } \\
(95 \% \mathrm{Cl})\end{array}$ \\
\hline \multicolumn{5}{|l|}{ Pulmonary function } \\
\hline \multirow[t]{3}{*}{ FVC (\%) } & Baseline & 14 & $82.6 \pm 19.6$ & - \\
\hline & After treatment & 14 & $88.0 \pm 14.4$ & $5.35(-0.04$ to 10.74$)$ \\
\hline & P-value ${ }^{\dagger}$ & 0.0651 & & \\
\hline \multirow[t]{3}{*}{ TLC (\%) } & Baseline & 10 & $86.3 \pm 21.4$ & - \\
\hline & After treatment & 10 & $86.2 \pm 19.0$ & $-0.13(-9.38$ to 9.12$)$ \\
\hline & P-value ${ }^{\dagger}$ & 0.9219 & & \\
\hline \multirow[t]{3}{*}{$\mathrm{FEV}_{1}(\%)$} & Baseline & 16 & $81.5 \pm 17.8$ & - \\
\hline & After treatment & 16 & $82.8 \pm 12.8$ & $1.31(-4.55$ to 7.17$)$ \\
\hline & P-value ${ }^{\dagger}$ & 0.7436 & & \\
\hline \multirow[t]{3}{*}{$\mathrm{SpO}_{2}(\%)$} & Baseline & 8 & $86.7 \pm 15.7$ & - \\
\hline & After treatment & 8 & $90.6 \pm 10.4$ & 3.86 ( -4.55 to 12.28$)$ \\
\hline & P-value ${ }^{\dagger}$ & 0.9453 & & \\
\hline \multirow[t]{3}{*}{$\mathrm{SaO}_{2}(\%)$} & Baseline & 7 & $95.3 \pm 2.0$ & - \\
\hline & After treatment & 7 & $95.8 \pm 1.0$ & $0.46(-1.64$ to 2.56$)$ \\
\hline & P-value ${ }^{\dagger}$ & 0.8125 & & \\
\hline \multirow[t]{3}{*}{$\mathrm{DLco}(\mathrm{mL} / \mathrm{min} / \mathrm{mmHg})$} & Baseline & 12 & $36.9 \pm 19.0$ & - \\
\hline & After treatment & 12 & $46.4 \pm 27.9$ & 9.51 ( -7.07 to 26.09$)$ \\
\hline & P-value ${ }^{\dagger}$ & 0.1763 & & \\
\hline \multicolumn{5}{|l|}{ Hemodynamics } \\
\hline \multirow[t]{3}{*}{ RAP $(\mathrm{mmHg})$} & Baseline & 17 & $8.0 \pm 4.7$ & - \\
\hline & After treatment & 17 & $5.4 \pm 2.2$ & $-2.65(-5.61$ to 0.31$)$ \\
\hline & P-value $^{\dagger}$ & 0.1225 & & \\
\hline \multirow[t]{3}{*}{ PAWP (mmHg) } & Baseline & 18 & $8.2 \pm 2.8$ & - \\
\hline & After treatment & 18 & $9.2 \pm 2.8$ & $1.06(-1$ to 3.11$)$ \\
\hline & P-value ${ }^{\dagger}$ & 0.3107 & & \\
\hline \multirow[t]{3}{*}{ mPAP $(\mathrm{mmHg})$} & Baseline & 20 & $44.9 \pm 14.2$ & - \\
\hline & After treatment & 20 & $31.4 \pm 8.6$ & $-13.5(-19.27$ to -7.73$)$ \\
\hline & P-value $^{\dagger}$ & 0.0001 & & \\
\hline \multirow[t]{3}{*}{$\mathrm{CO}(\mathrm{L} / \mathrm{min})$} & Baseline & 18 & $4.1 \pm 2.2$ & - \\
\hline & After treatment & 18 & $5.3 \pm 1.7$ & $1.23(-.044$ to 2.9$)$ \\
\hline & P-value ${ }^{\dagger}$ & 0.0335 & & \\
\hline \multirow[t]{3}{*}{ PVR (dyn $\left.\cdot s \cdot \mathrm{cm}^{-5}\right)$} & Baseline & 19 & $949.2 \pm 694.5$ & - \\
\hline & After treatment & 19 & $385.7 \pm 247.7$ & $-563.53(-917.31$ to -209.74$)$ \\
\hline & P-value ${ }^{\dagger}$ & 0.0033 & & \\
\hline \multirow[t]{3}{*}{ Saturation (\%) } & Baseline & 8 & $91.1 \pm 14.9$ & - \\
\hline & After treatment & 8 & $95.3 \pm 1.7$ & $4.25(-8.27$ to 16.77$)$ \\
\hline & P-value ${ }^{\dagger}$ & 1.0000 & & \\
\hline \multirow[t]{3}{*}{ Cardiac index $\left(\mathrm{L} / \mathrm{min} / \mathrm{m}^{2}\right)$} & Baseline & 20 & $2.5 \pm 1.0$ & - \\
\hline & After treatment & 20 & $4.3 \pm 3.6$ & $1.82(-0.02$ to 3.66$)$ \\
\hline & P-value ${ }^{\dagger}$ & 0.0019 & & \\
\hline \multirow[t]{3}{*}{$\mathrm{SvO}_{2}(\%)$} & Baseline & 13 & $68.0 \pm 13.7$ & - \\
\hline & After treatment & 13 & $74.5 \pm 6.3$ & 6.55 (-3.31 to 16.42$)$ \\
\hline & $\mathrm{P}_{\text {-value }}{ }^{\dagger}$ & 0.2439 & & \\
\hline \multicolumn{5}{|l|}{ Echocardiography } \\
\hline \multirow[t]{3}{*}{ TRPG $(\mathrm{mmHg})$} & Baseline & 22 & $62.3 \pm 25.1$ & - \\
\hline & After treatment & 22 & $46.9 \pm 22.2$ & $-15.41(-24.18$ to -6.63$)$ \\
\hline & P-value ${ }^{\dagger}$ & 0.0006 & & \\
\hline \multicolumn{5}{|l|}{ Clinical status } \\
\hline 6MWD (m) & Baseline & 5 & $324.6 \pm 187.1$ & - \\
\hline & After treatment & 5 & $434.8 \pm 105.6$ & $110.2(-30.67$ to 251.07$)$ \\
\hline & P-value $^{\dagger}$ & 0.0625 & & \\
\hline BNP (pg/mL) & Baseline & 16 & $353.9 \pm 339.0$ & - \\
\hline & After treatment & 16 & $145.2 \pm 187.7$ & $-208.63(-357.74$ to -59.51$)$ \\
\hline & $\mathrm{P}_{\text {-value }}{ }^{\dagger}$ & 0.0182 & & \\
\hline
\end{tabular}

Data given as mean \pm SD. ${ }^{+P}$ aired Wilcoxon test. BNP, brain natriuretic peptide; DLco, diffusing capacity for carbon monoxide; $\mathrm{FEV}_{1}$, forced expiratory volume in $1 \mathrm{~s}$; $\mathrm{FVC}$, forced vital capacity; $\mathrm{SaO}_{2}$, blood oxygen saturation; $\mathrm{SpO}_{2}$, percutaneous oxygen saturation; $\mathrm{SvO}_{2}$, mixed venous oxygen saturation; TLC, total lung capacity. Other abbreviations as in Table 1. 


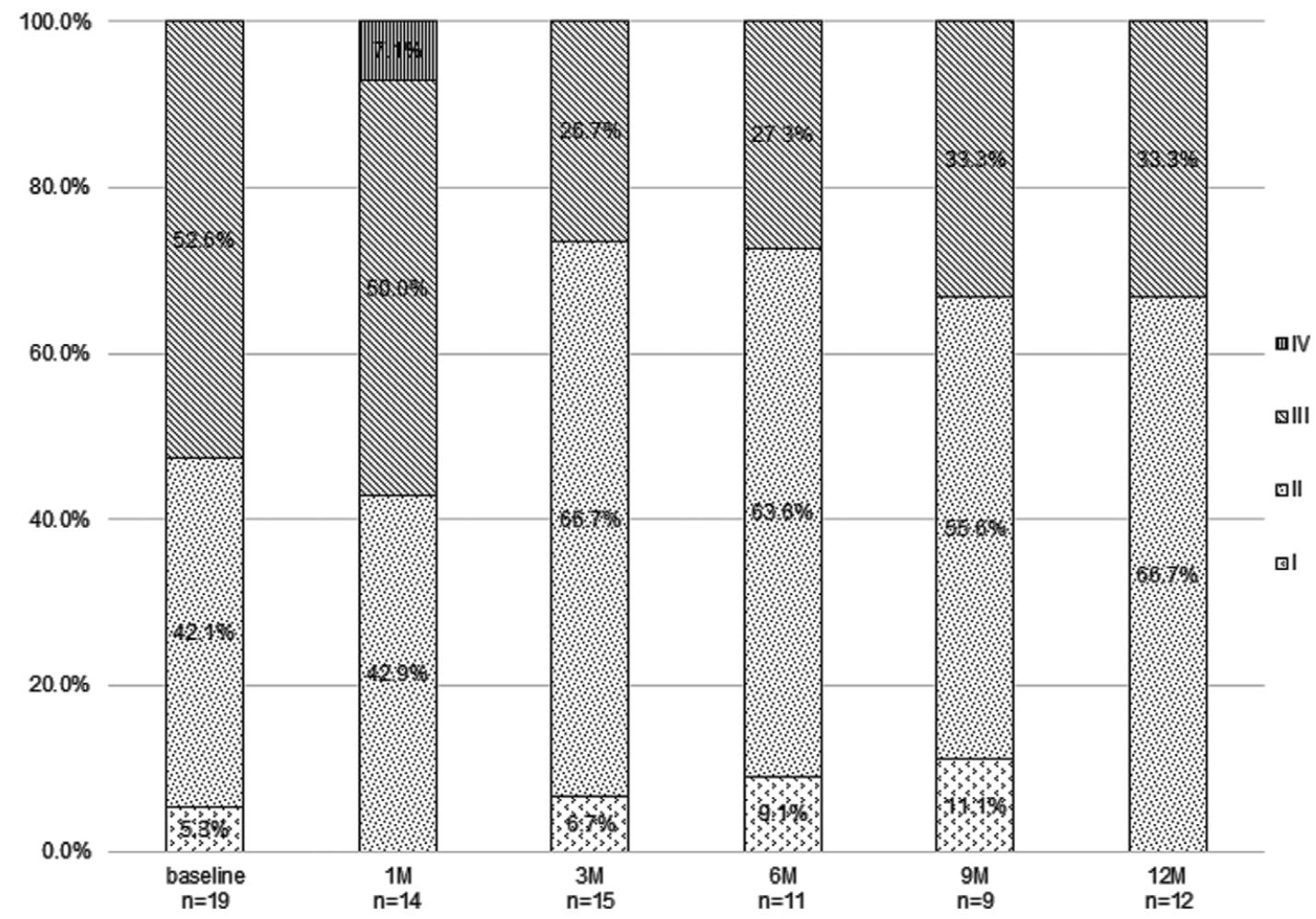

Figure 2. Change in World Health Organization pulmonary hypertension functional class after combination therapy. M, month(s).

the present study were headache $(8.3 \%)$ and face edema $(4.2 \%)$. Headache and edema also tended to be more common in Japanese patients with vasodilator combination therapy. From these results, ambrisentan and PDE5 inhibitor combination therapy is tolerated by the majority of Japanese patients, and new AE were not seen. Thus, this combination therapy is a reasonable therapeutic option for Japanese patients.

In the present efficacy analysis, 6MWD, WHO-FC, BNP, TRPG and hemodynamic parameters were examined at baseline and after treatment in all patients and in relation to the presence and absence of CTD, to follow changes in symptoms after treatment. In particular, mPAP was decreased by $13.5 \mathrm{mmHg}$ from baseline to post-treatment assessment. A single-center blinded evaluation of patients enrolled in the AMBITION study showed that initial combination therapy in 19 patients significantly changed mPAP from $55 \pm 11 \mathrm{mmHg}$ to $37 \pm 11 \mathrm{mmHg}$ after 6 months of treatment. ${ }^{12}$ In a retrospective study, Ogawa et al reported an association between high survival rate $(96 \%$ at 5 years) in 56 Japanese patients with idiopathic/heritable PAH and improvement due to PAH-targeted drugs in hemodynamics parameters such as mPAP, PVR, and cardiac index after treatment. 2,3 The Japan PH Registry (JAPHR), the first organized multicenter registry for PAH in Japan, noted an excellent survival rate (i.e., 95.7\% at 3 years) and an improvement in hemodynamics parameters by initial combination therapy; and an AMBITION post-hoc analysis showed survival improvement due to initial combination therapy. ${ }^{13,14}$ Thus, the initial combination therapy might be associated with a survival advantage and the treatment strategy of initial combination therapy and the follow-up based on the improvement in hemodynamic status are important. A prospective investigation is needed to demonstrate the beneficial effect of improvement of hemodynamic parameters for favorable long-term outcome in $\mathrm{PAH}$ patients.

\section{Study Limitations}

There was a limitation of the efficacy data under this surveillance because each clinical parameter was not measured consistently; that is, data were collected at each investigator's discretion. The appropriateness of combination therapy in each case (e.g., initial combination therapy for patients with WHO-FC I) was not considered because this surveillance reflected the actual clinical practice in a real-world setting compared with the registration trial. We collected case records for 60 patients from 5 expert centers as a special drug use investigation. The generalization of obtained results should be carefully interpreted because of the small sample size and lack of control group (i.e., monotherapy), although 3 expert centers among the participating institutions were regarded as nationwide representative institutions, and in their epidemiologic study the 1-, 3-, 5-, and 10-year survival rates of Japanese patients were $97.9 \%, 92.1 \%, 85.8 \%$, and $69.5 \%$, respectively. ${ }^{3}$ Furthermore, this study could not assess fully the influence of the combination itself compared with monotherapy and combination type (i.e., initial or sequential combination) and concomitant medications, except for PDE5 inhibitors or changes in concomitant drugs. Thus, the improvement of clinical parameters by initial or sequential combination 
therapy should be evaluated in a large-scale prospective trial or Japanese registry such as JAPHR. ${ }^{14}$ Sitbon et al reported that the initial combination of oral PAH-targeted medications consisting of ERA plus PDE5 inhibitors was beneficial in newly diagnosed patients with $\mathrm{PAH}$, and that the combination with tadalafil produced a greater hemodynamic improvement than that with sildenafil irrespective of ERA brand, using real-world clinical data. ${ }^{15}$ Determination of which combination is the best or least useful is highly warranted because we could not compare ERA in combination with PDE5 inhibitors in the present survey, because this retrospective survey was conducted as PMS only for ambrisentan under GPSP, and the dose of each PDE5 inhibitor was not sufficiently investigated. Additionally, the clinical classification of PAH in this survey was carried out according to an earlier classification method used in a Japanese phase 3 clinical trial. ${ }^{9}$ This method is different from the current classification.

\section{Conclusions}

Ambrisentan combination therapy with tadalafil or sildenafil has been shown to be effective and safe. The safety profiles are consistent with that observed in previous clinical trials of combination therapies. Thus, ambrisentan combination therapy with tadalafil or sildenafil is a reasonable therapeutic option for Japanese patients.

\section{Acknowledgments}

GlaxoSmithKline K.K. funded this surveillance. Trademarks are owned by or licensed to the GSK group of companies.

\section{Disclosures}

The study was funded by GlaxoSmithKline K.K. K.U., T.T. and A.N. are paid employees of GlaxoSmithKline K.K., Tokyo, Japan and K.U. holds shares in GlaxoSmithKline K.K. M.K. has received a research grant from Actelion Pharmaceuticals Japan (Tokyo, Japan), T.S. has received a research grant and lecture fees from Actelion Pharmaceuticals Japan (Tokyo, Japan), H.M. has received a lecture fees from Nippon Shinyaku (Kyoto, Japan), Bayer Yakuhin (Osaka, Japan), Pfizer Japan (Tokyo, Japan), and Actelion Pharmaceuticals Japan (Tokyo, Japan), K.F. has received a research grant from Bayer Yakuhin (Osaka, Japan), Pfizer Japan (Tokyo, Japan) and lecture fees from Bayer Yakuhin (Osaka, Japan). The other authors declare no conflicts of interest.

\section{Author Contributions}

K.U., T.T. conceived and designed the study. M.K., T.S., H.M., K.Y., T.I., K.F. performed the study as investigators. K.U., T.T managed and analyzed the data. M.K., T.S., H.M., K.Y., T.I., K.F., K.U., T.T., A.N. interpreted the data. M.K., T.S., H.M., K.Y., T.I., K.F., K.U., T.T., A.N. wrote the paper.

\section{References}

1. D’Alonzo GE, Barst RJ, Ayres SM, Bergofsky EH, Brundage $\mathrm{BH}$, Detre KM, et al. Survival in patients with primary pulmonary hypertension: Results from a national prospective registry. Ann Intern Med 1991; 115: 343-349.

2. Ogawa A, Ejiri K, Matsubara H. Long-term patient survival with idiopathic/heritable pulmonary arterial hypertension treated at a single center in Japan. Life Sci 2014; 118: 414-419.

3. Ogawa A, Satoh T, Tamura Y, Fukuda K, Matsubara H. Survival of Japanese patients with idiopathic/heritable pulmonary arterial hypertension. Am J Cardiol 2017; 119: 1479-1484.

4. Galiè N, Barberà JA, Frost AE, Ghofrani HA, Hoeper MM, McLaughlin VV, et al. Initial use of ambrisentan plus tadalafil in pulmonary arterial hypertension. N Engl J Med 2015; 373: 834844.

5. Pulido T, Adzerikho I, Channick RN, Delcroix M, Galiè N, Ghofrani HA, et al. Macitentan and morbidity and mortality in pulmonary arterial hypertension. $N$ Engl J Med 2013; 369: $809-818$.

6. Sitbon O, Channick R, Chin KM, Frey A, Gaine S, Galiè N, et al. Selexipag for the treatment of pulmonary arterial hypertension. $N$ Engl J Med 2015; 373: 2522-2533.

7. Fox BD, Shtraichman O, Langleben D, Shimony A, Kramer MR. Combination therapy for pulmonary arterial hypertension: A systematic review and meta-analysis. Can J Cardiol 2016; 32: $1520-1530$

8. Galie N, Humbert M, Vachiery JL, Gibbs S, Lang I, Torbicki A, et al. 2015 ESC/ERS Guidelines for the diagnosis and treatment of pulmonary hypertension: The Joint Task Force for the Diagnosis and Treatment of Pulmonary Hypertension of the European Society of Cardiology (ESC) and the European Respiratory Society (ERS): Endorsed by: Association for European Paediatric and Congenital Cardiology (AEPC), International Society for Heart and Lung Transplantation (ISHLT). Eur Heart $J$ 2016; 37: 67-119.

9. Yoshida S, Shirato K, Shimamura R, Nakahara N, Iwase T, Nakajima H. Efficacy, safety, and pharmacokinetics of ambrisentan in Japanese adults with pulmonary arterial hypertension. Curr Med Res Opin 2011; 27: 1827-1834.

10. Takahashi T, Hayata S, Kobayashi A, Onaka Y, Ebihara T, Hara T. Surveillance on the safety and efficacy of ambrisentan (Volibris tablet $2.5 \mathrm{mg}$ ) in patients with pulmonary arterial hypertension in real clinical practice: Post-marketing surveillance (Interim analysis report). Clin Drug Investig 2018; 38: 219-229.

11. Fukuda K, Itoh H, Ueda H, Ogino H, Kuwana M, Sato T, et al. Guidelines for treatment of pulmonary hypertension (JCS2017/ JPCPHS 2017). http://www.j-circ.or.jp/guideline/pdf/JCS2017 fukuda h.pdf\#search= $\% 27 \% \mathrm{E} 8 \% 82 \% \mathrm{BA} \% \mathrm{E} \% \mathrm{AB} \% 98 \% \mathrm{E} 8 \% \overline{\mathrm{A}}$ $1 \% 80 \% \mathrm{E} 5 \% 9 \mathrm{C} \% \mathrm{~A} 7 \% \mathrm{E} 7 \% 97 \% 87+\% \mathrm{E} 3 \% 82 \% \mathrm{AC} \% \mathrm{E} 3 \% 82 \% \mathrm{~A} 4$ $\%$ E3\%83\%89\%E3\%83\%A9\%E3\%82\%A4\%E3\%83\%B3\%27 (accessed February 8, 2019) (in Japanese).

12. Bachetti C, Manes A, Dardi F, Palazzini M, Mazzanti G, Rinnaldi A, et al. Comparison between initial combination therapy and initial monotherapy in pulmonary arterial hypertension: A single centre blinded evaluation of patients enrolled in the AMBITION study. Am J Respir Crit Care Med 2015; 191: A4779.

13. Hoeper MM, McLaughlin VV, Barberá JA, Frost AE, Ghofrani HA, Peacock AJ, et al. Initial combination therapy with ambrisentan and tadalafil and mortality in patients with pulmonary arterial hypertension: A secondary analysis of the results from the randomised, controlled AMBITION study. Lancet Respir Med 2016; 4: 894-901.

14. Tamura Y, Kumamaru H, Satoh T, Miyata H, Ogawa A, Tanabe N, et al. Effectiveness and outcome of pulmonary arterial hypertension-specific therapy in Japanese patients with pulmonary arterial hypertension. Circ J 2018; 82: 275-282.

15. Sitbon O, Sattler C, Bertoletti L, Savale L, Cottin V, Jaïs X, et al. Initial dual oral combination therapy in pulmonary arterial hypertension. Eur Respir J 2016; 47: 1727-1736.

\section{Supplementary Files}

Please find supplementary file(s);

http://dx.doi.org/10.1253/circrep.CR-19-0029 